\title{
Effect of Blockage of the Ducts of the Vomeronasal Organ on LH Plasma Levels during the "Whitten Effect" in Does
}

\author{
Kenneth Kurt Booth ${ }^{1}$ and Edward Cottington Webb ${ }^{2}$ \\ ${ }^{1}$ Department of Anatomy and Physiology, Faculty of Veterinary Science, University of Pretoria, Private Bag X04, \\ Onderstepoort 0110, South Africa \\ ${ }^{2}$ Department of Animal and Wildlife Sciences, Faculty of Natural and Agricultural Sciences, University of Pretoria, \\ Pretoria 0001, South Africa \\ Correspondence should be addressed to Kenneth Kurt Booth, ken.booth@up.ac.za \\ Received 30 April 2010; Accepted 13 July 2010 \\ Academic Editor: Stefan Schlatt
}

Copyright $\odot 2011$ K. K. Booth and E. C. Webb. This is an open access article distributed under the Creative Commons Attribution License, which permits unrestricted use, distribution, and reproduction in any medium, provided the original work is properly cited.

\begin{abstract}
Eighteen mature, nonpregnant, and indigenous South African does were randomly divided into two groups to test if their vomeronasal organs exert an influence on LH plasma levels during a Whitten effect experimental trial. Does in the treatment (VNO ablated) group had their vomeronasal organs rendered nonfunctional by cauterization of the nasoincisive duct under surgical anesthesia. Does in the control group had their nasal civities irrigated with physiological saline under surgical anesthesia. All does were synchronized into oestrus and introduced to bucks one day prior to their expected second oestrus cycle. Successful matings were recorded. Timely blood samples were collected during each of the five days before and five days after buck introduction. Blood plasma concentrations of estradiol and LH were determined by radioimmunoassay. Analysis of variance between groups demonstrated that the does in the VNO ablated group did not demonstrate any interest in mating, did not become pregnant, and did not demonstrate the primary increase in tonic plasma levels of LH that is necessary for ovulation to occur. By contrast, all of the does in the control group demonstrated successful matings, became pregnant, and demonstrated typical primary tonic level increases and preovulation surges in LH. Thus, it was concluded that the vomeronasal organ modulates the primary increase in tonic levels of $\mathrm{LH}$ and thus influences ovulation that occurs during the Whitten effect in South African indigenous does.
\end{abstract}

\section{Introduction}

The "Whitten (male) effect" results in the synchronization of ovulation in a group of anoestrous female animals in the presence of a novel, sexually matured male of the same species [1]. This male effect has been researched in laboratory rodents [2-4] and its principles have been employed in the teasing technique to synchronize parturitions in flocks of ewes [5-9] and herds of does [10, 11].

In all studies conducted, this male effect results in an elevation of plasma concentrations of Luteinizing Hormone [9, $12-14]$, which is a prerequisite in the sequence of endocrine events leading to ovulation [15]. The secretion of Luteinizing Hormone (LH) from the gonadotrophs in the Pars Distalis of the Hypophysis (pituitary gland) is controlled entirely by the secretion of Luteinizing Hormone Releasing Hormone
(LHRH) from the parvicellular neurons of the hypothalamus [16].

Many factors have regulatory nervous inputs onto the neurosecretory cells of the hypothalamus. Studies have investigated the possibility that the sight, sound, and/or smell of the novel male could all have stimulatory inputs onto the hypothalamus that could modulate the secretion of LH [1721]. However, several studies suggested that the LH response in females resulted from pheromones emanating from the male animal [17, 22-24]. Pheromones, which are detected by the vomeronasal organ [25], are known to influence a variety of animal activities from sexual maturation to maternal offspring recognition during nursing [3, 26-41].

The vomeronasal organ (VNO) in small ruminants is morphologically constructed for the detection of pheromones. It consists of two blind ending, epithelial-lined tubes that 
are enclosed in a "C" -shaped cartilage, situated on each side of the base of the nasal septum [42]. Each tube has only one rostral opening into the nasoincisive duct that, in turn, opens onto the floor of the nasal cavity, just caudally to the nasal vestibule and into the oral cavity on each side of the incisive papillae, just caudally to the dental pad [42]. The sensory epithelium, which lines one side of each VNO, possesses chemical receptors that are specific for pheromones [43, 44], and these specific receptors have only been identified in the epithelial lining of the VNO $[44,45]$. This sensory epithelium gives origin to nerves that pass through the cribriform plate of the ethmoid bone in close association with the nerves arising from the olfactory region of the nasal cavity [46]. The vomeronasal nerves bend around the dorsal margin of the olfactory bulb to reach the accessory olfactory bulb, which lies on the dorsal surface of the olfactory peduncle at the caudal margin of the olfactory bulb [47]. Nerve fibers from the accessory olfactory bulb project to the medial and cortical amygdaloid nuclei, which give rise to fibers to the medial preoptic area and the medial hypothalamus [48]. This pathway from the accessory olfactory bulb is distinct and separate from the connections of the main olfactory bulb to other central cortical areas [49].

Thus, the VNO is connected to areas of the brain identified with gonadotropin releasing hormone production [50]. An LH surge has been produced by stimulation of the accessory olfactory bulb [51], as well as any of its cortical projection areas such as the medial and cortical amygdaloid nuclei $[52,53]$ and the medial portion of the bed nucleus of the stria terminalis $[52,54]$. The accessory olfactory bulb receives all of its sensory input from the VNO [47].

It has also been demonstrated that the LHRH secretory hypothalamic neurons migrate from the VNO rudiment in the embryonic nasal placode to the hypothalamic region of the embryonic brain via an aberrant branch of the caudal vomeronasal nerve [55-59]. This aberrant branch travels separately and directly to the hypothalamic region without first passing to the accessory olfactory lobe, as is the case for all the other vomeronasal nerves [60]. Thus, there is a possibility that a direct connection exists between the VNO and the LHRH neurons of the hypothalamus that would influence LH secretion through pheromonal stimulation in the adult animal. Therefore, the purpose of this investigation was to determine what influence is exerted by a functional VNO on plasma levels of LH during the "Whitten effect" in does.

\section{Materials and Methods}

2.1. Animals. The Animal Use and Care Committee of the Faculty of Veterinary Science at the University of Pretoria approved this research project in goats. The experiment was initiated during the spring season in the southern hemisphere (September to November), in an attempt to insure that all does would be in the anoestrus stage of their reproductive cycle. Eighteen sexually mature, nonpregnant, and indigenous South African does of the same age (three years of age) were acquired from the Mara Agricultural Development Center, where yearly breeding records demonstrated that each doe had a minimum of two successful kidding seasons. At the Faculty of Veterinary Science within the University of Pretoria, the does were randomly divided into either a VNO-ablated group or a control group. Random selection was achieved by blindly drawing each separate animal ear tag number and sequentially allocating the animal to either a control group or a VNO-ablated group. The VNO of each of the nine does in the VNO-ablated group was rendered nonfunctional by means of surgical cauterization of the nasopalatine duct in the small animal surgical unit at the Faculty of Veterinary Science, University of Pretoria. Anesthesia was produced in each VNO-ablated doe via an intravenous injection of Thiopentone $(15 \mathrm{mg} / \mathrm{kg}$ body weight). The oral openings (right and left) of the nasopalatine ducts were located just caudal to the dental pad, on either side of the incisive papilla. The ends of a cauterizing forceps were inserted to the level of the nasal opening of the ducts. Cauterization was then initiated (using the maximum power setting) while slowly withdrawing the forceps through the oral openings of the ducts. This procedure completely closed the duct to each VNO situated on either side of the nasal septum. One month after the above procedure was completed, the success of the duct closure was determined by observing the healing of the oral mucosa over the oral opening of the nasopalatine ducts. All does assigned to the VNO-ablated group demonstrated complete closure of the vomeronasal ducts. Thus, the does in this group had normal olfactory ability; however, sensory information could not reach their vomeronasal organs. The nine does in the control group were anesthetized as in the treatment group; but their nasal cavities were irrigated only with $2 \mathrm{~mL}$ of normal saline. Thus, both the olfactory system and the vomeronasal system remained functional in this group of does.

2.2. Housing. After recovery from anesthesia, all does were transferred to and housed together in the Small Stock Unit (covered research arena) at the Hatfield Experimental Research Farm of the University of Pretoria, where they remained isolated from bucks for 30 days. This postsurgical healing period allowed for sufficient animal adaptation to the experimental surroundings. During this time, all does were fed a balanced, mixed, and pelleted maintenance ration, allowed free access to water, and were vaccinated against pulpy kidney and pasteurella.

2.3. Oestrus Synchronization and Blood Sampling. All does were sonar scanned for pregnancy before synchronization was begun. Oestrus synchronization was accomplished by two intramuscular injections $(0.5 \mathrm{~mL}$ per doe, per injection) of Lutalyse (Pharmacia Animal Health-a division of Pfizer Laboratories, Craighall, Johannesburg, South Africa), administered 10 days apart. The first injection occurred at 12:00 $\mathrm{h}$ and this was considered time $0: 00 \mathrm{~h}$ of Day 0 of the trial. Thus, the second injection of Lutalyse was given at 12:00 h of Day 10 of the trial. Vaginal sponges ("Ovakron tampons": DNAfrica Anipharm Pty. Ltd., Pretoria, South Africa), containing $40 \mathrm{mg}$ flugestone acetate, were inserted into the vagina of each doe immediately after the second 
injection of Lutalyse and removed 14 days later $(12: 00 \mathrm{~h}$ of Day 24 of the trial). The does were allowed a 21 day recovery period, after which the bucks were introduced at 12:00 h of Day 45 of the trial. Thus, the does were allowed one full oestrus cycle, prior to the introduction of the bucks, in order to eliminate possible carry-over effect of the Lutalyse and progesterone treatments.

All blood samples were collected via External Jugular Venipuncture using $10 \mathrm{~mL}$ heparinized Vacutainer tubes (Becton, Dickinson and Company, Plymouth, United Kingdom). Blood sampling (12 hourly intervals) commenced at $12: 00 \mathrm{~h}$ on Day 40 of the trial and continued until 24:00 h of Day 44, after which the blood sampling frequency was increased to every four hours for the next 36 hours. After the blood samples were collected at 12:00 h of Day 45 , six matured Saanen bucks (from the university's male breeding stock) were introduced to all the does that were housed together at the Small Stock Unit. Constant behavioral observations of the bucks with the does were made and each doe undergoing a successful mating was recorded during the first 36 hours after the introduction of the bucks. The bucks remained with the does for three weeks from introduction and then males and females were separated for the remainder of the experiment. After collection of the blood samples at 20:00 h on Day 45, the frequency of blood collection was decreased to every twelve hours for the next three days. All blood samples were immediately centrifuged and the collected plasma samples were stored at -15 degrees Celsius for subsequent analysis for Estradiol and LH concentrations.

Ten weeks after the bucks were introduced, the does were sonar scanned for pregnancy. This was used as a preliminary indirect parameter to assess the response of the does subsequent to the introduction of bucks during the nonbreeding season.

2.4. Analyses of Plasma Samples. Estradiol and LH plasma concentrations were determined using the Beckman Coulter Access Immunoassay System (a paramagnetic particle, chemiluminescent immunoassay). The data were analyzed by means of the ANOVA procedure on SAS (2001). Categorical data were analyzed by means of log-linear analysis and multiple comparisons tested by means of the Bonferroni technique for unbalanced data.

\section{Results}

3.1. Conception Rates. Sonar scans, performed before synchronization began, demonstrated no pregnancies in any doe within either the control or VNO-ablated groups. All does in both the VNO-ablated and control groups demonstrated negligible concentrations of $\mathrm{LH}$, indicative of anoestrus, prior to the introduction of the bucks (Figure 2). One doe in the VNO-ablated group died of pulpy kidney during the postsurgical healing period. Records from successful matings demonstrated that none of the does in the VNO-ablated group showed any interest in mating and none were mated during the first 36 hours after the introduction of the bucks. This was in contrast to the does in the control group, which were all mated during the first 36 hours after the introduction of the bucks. Ultrasonography, performed on the does ten weeks after the introduction of the bucks, indicated that none $(0.0 \%)$ of the eight remaining does in the $\mathrm{VNO}$-ablated group became pregnant. All (100.0\%) of the nine does in the control group were found to be pregnant.

3.2. Estradiol and Luteinizing Hormone Concentrations. Over all mean estradiol concentration in blood samples from does in the control group $(78.515 \mathrm{pmol} / \mathrm{L})$ did not differ compared to the does in the VNO-ablated group $(75.318 \mathrm{pmol} / \mathrm{L})$. When estradiol concentrations were compared across time of sampling, there were no significant differences between the VNO-ablated and control groups (Figure 1). Both groups demonstrated elevated concentrations of estradiol prior to the introduction of the bucks and a significant drop of estradiol concentrations at four hours after the introduction of the bucks. Estradiol levels stabilized between four and 20 hours after buck introduction and then another drop in estradiol concentrations occurred at 24 hours after the introduction of the bucks (Figure 1).

Over all mean LH concentrations were also only marginally higher $(P=.10)$ in the control does $(0.372 \mathrm{iu} / \mathrm{L})$ when compared to the VNO-ablated does $(0.289 \mathrm{iu} / \mathrm{L})$. Comparisons of the LH concentrations during the 32 hours period after the introduction of the bucks demonstrated a significant absence $(P<.027)$ of detectable LH concentrations in the VNO-ablated group during the first 16 hours (Figure 2), while the control group demonstrated an elevation in plasma concentrations of LH during this time period. This was followed by a surge in LH levels in both groups (Figure 2) during the last 16 hours of the bloodsampling period. There were no significant differences in LH concentrations between groups during this surge in LH concentrations, within the last 16 hours of the bloodsampling period.

\section{Discussion}

In this study, the $100 \%$ conception rate obtained among the does within the control group indicated that all does in this group ovulated. Similarly, the $0 \%$ conception rate among the anoestrus does within the $\mathrm{VNO}$-ablated group of this experiment was identical to the $0 \%$ ovulation rate in anoestrus female rats in which the nasal openings of the VNO were sealed by electrocauterization [3].

It might be argued that ovulation could have occurred without being accompanied by oestrus. However, most silent ovulations occur between 41 hours to a few days after the introduction of males $[7,61,62]$. The males in this study were introduced just prior to the expected second oestrus cycle after synchronization and remained with the does for three weeks. Thus, the males were with the females through the second and, where applicable, the third ovulation period after synchronization. Also, the male: female ratio was $1: 3$ and therefore was low enough to ensure that the males would have serviced all females that had ovulated. 


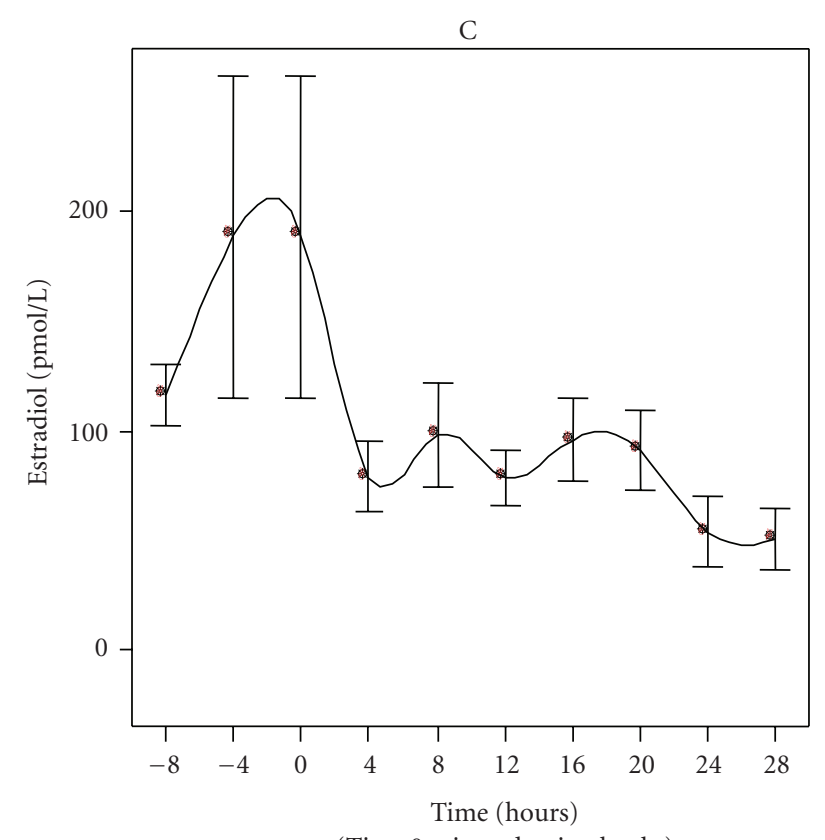

( Time 0 = introduction bucks)

(a)

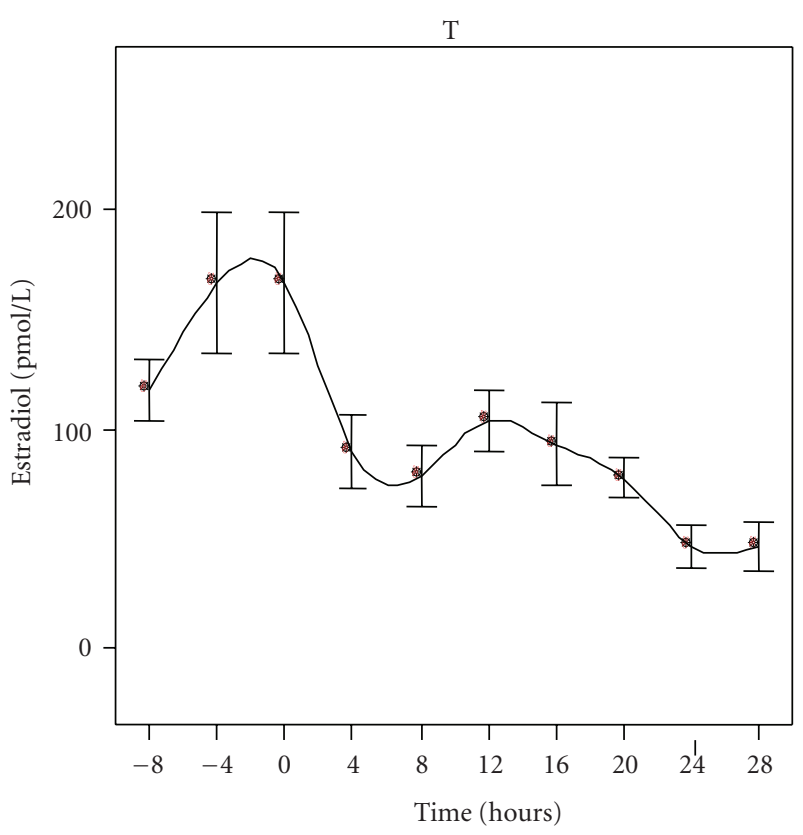

(Time 0 = introduction bucks)

FIGURE 1: Mean plasma concentrations and standard deviations of estradiol in does in the control (C) and treatment (T) groups versus hours before and after the introduction of bucks.

Since all of the anoestrus does in the VNO-ablated group did not become pregnant, as compared to the $100 \%$ conception rate of the anoestrus does in the control group, it does appear that the VNO is involved in the synchronization of oestrus and that a functional VNO has an influence on ovulation, during the male effect, in anoestrus, indigenous, South African goats. Similarly, the observations that the anoestrus does in the VNO-ablated group (does with functional main olfactory systems) did not demonstrate any aspects of the Whitten effect indicates that the main olfactory system is not involved in the Whitten effect in the South African indigenous goat.

The male effect is known to cause increased plasma concentrations of $\mathrm{LH}$, which are a prerequisite for ovulation $[9,12-15]$. There are normally two increases in plasma concentrations of LH in the ewe: a primary increase in tonic levels, that is, lower in plasma concentration than the following preovulatory surge [12]. The primary increase is believed to sensitize the ovary and to be necessary for ovulation to occur during the preovulatory surge $[9,13]$. The anoestrus does, in the control group in this investigation, demonstrated two elevations in plasma concentrations of LH similar to the descriptions in the sheep [12]. The primary increase in tonic levels of LH began at four hours, reached a peak at eight hours, and decreased to minimal values at 16 hours after the introduction of the bucks. This rise in tonic levels of LH was followed by a much higher preovulatory surge that reached a peak at 24 hours after the introduction of the bucks (expected day of the second ovulation after synchronization of the trial). The time between the introduction of males and the initial rise in $\mathrm{LH}$ plasma concentrations has been reported in ewes to vary from 10 minutes to 52 hours [7, 9, 12-14], with the average delay being 17-18 hours [9]. A male-induced ovulation in ewes has been considered to be the result of a prevulatory surge of LH occurring within 30 hours of introduction of the ram [63]. Thus, the appearance of an initial rise in plasma concentration of $\mathrm{LH}$ occurring within the first 16 hours, followed by a more pronounced surge in LH plasma concentrations occurring at 24 hours after the introduction of the bucks, in the does within the control group in this investigation, is consistent with that reported in ewes.

When the overall means of plasma LH levels were compared between groups, there was a significant difference between groups only at the 10 percent confidence level. This observation of nonsignificance was not supported by the significant difference in conception rates between the two groups in this experiment. Therefore, treatment interactions were statistically analyzed and when the plasma LH levels between groups were compared across time of sampling, there was a highly significant $(P<.027)$ absence of any detectable plasma LH levels during the first 16 hours after the introduction of the bucks among the does in the VNOablated group. This was similar to the absence of an LH surge in female rats with their VNOs removed when compared to the LH surges in female rats with intact VNOs [64]. Since it has been demonstrated in studies with sheep that only ewes which ovulated had a primary increase in tonic levels of LH [9], the absence of an increase in the tonic levels of $\mathrm{LH}$, among the does in the $\mathrm{VNO}$-ablated group in this experiment, would explain the $0 \%$ conception rate among the anoestrus does in this group. The VNO-ablated group 


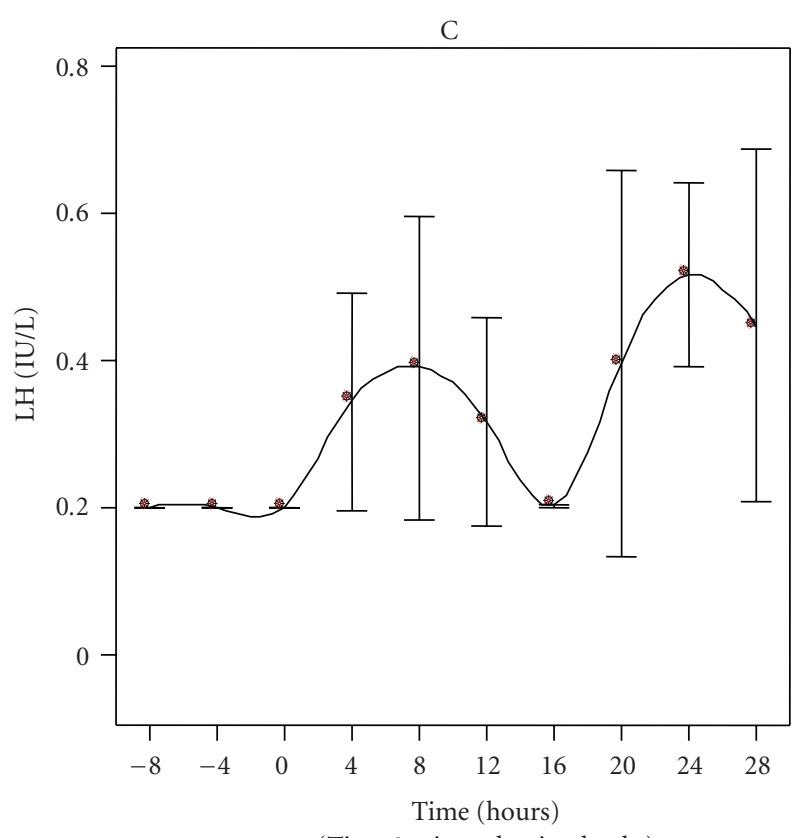

( Time 0 = introduction bucks)

(a)

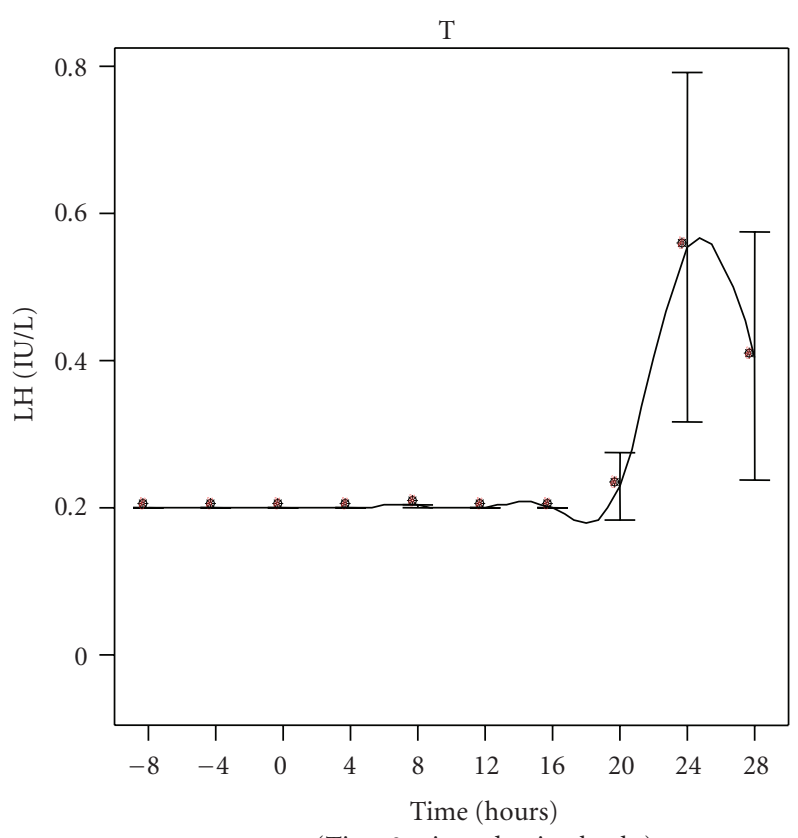

(Time 0 = introduction bucks)

(b)

Figure 2: Mean plasma concentrations and standard deviations of LH in does in the control (C) and the treatment (T) groups versus hours before and after the introduction of bucks.

did not have the "ovarian priming effect" of the primary increased in tonic levels necessary for ovulation to occur during the surge of LH and, therefore, did not ovulate nor become pregnant.

This absence of an increase in the tonic levels of $\mathrm{LH}$ occurred only in the group of does with blocked vomeronasal organs, in spite of the fact that all other sensory modalities were operational in this group. Thus, it does appear that the vomeronasal organ modulates the increase in tonic levels of LH required for ovulation during the male effect in indigenous South African goats. This modulation is hypothesized to result from the direct neuronal connection existing between the VNO sensory epithelium and the LHRH hypothalamic neurons that was established by the embryonic migrations of the LHRH neurons along a branch of the caudal vomeronasal nerve, a branch which completely bypasses the accessory olfactory lobe and its subsequent cortical nerve projections [55-60]. This hypothesis supports the "VNO-mediated LHRH release" conclusions drawn from a study in female rats, in which the LH surge in the treatment group, with their VNOs removed, was significantly lower than the normal LH surge in the control group, with intact VNOs [64].

Although the VNO-ablated group did not demonstrate an increase in the tonic levels of $\mathrm{LH}$, this group did demonstrate a preovulatory surge at the same time and magnitude as the control group. This preovulatory surge could have resulted from the positive feedback effects of normal oestrogen secretion from the ovaries, as well as, from the additive stimulatory inputs onto the hypothalamic neurons by such factors as sight, sound, or even smell (olfactory stimulation) from the sexual activities of the males during the period of introduction [20, 65-70]. In goats, a combination of exteroceptive factors from the buck are known to cause maximal stimulation of oestrus and ovulation in does [71]. Thus, although absence of stimulation from the VNO resulted in absence of an increase in tonic levels of $\mathrm{LH}$, additive sensory input from other factors onto the LHRH hypothalamic neurons caused the preovulatory surge of $\mathrm{LH}$ in the $\mathrm{VNO}$-ablated group of does similar to the preovulatory surge in LH in the control group in this experiment. However, these additive stimuli were not sufficient to evoke ovulation without the increase in tonic levels of LH brought about by sensory stimulation from the VNO.

It might be considered that the LH differences could be due to differences in ovarian function between the two groups. However, estradiol concentrations have been used as an indicator of ovarian function [7]. The estradiol levels of all the does in this experiment were demonstrated to be normal and there were no significant differences between the two groups. This was similar to the no changes in the fluctuating pattern of estradiol concentrations when ewes were exposed to rams [7]. Thus, normal ovarian function occurred in both groups of does during this investigation.

\section{Conclusions}

Therefore, it was concluded that the main olfactory system is not involved in the Whitten effect in the South African indigenous goat. It was also concluded that blockage of the vomeronasal ducts results in an absence of conception, 
which resulted from an absence in the increase in tonic levels of LH from the pituitary gland required for ovulation to occur during the Whitten (male) effect in anoestrus, South African indigenous goats. Thus, the VNO modulates the primary increase in tonic levels of LH necessary for ovulation to occur in the South African indigenous goat. This modulation is hypothesized to occur via a direct nervous pathway from the VNO to the hypothalamus in the adult that was established by the embryonic migration of the LHRH secretory neurons. However, additive sensory input onto the LHRH hypothalamic neurons from other exteroceptive factors modulates the preovulatory surge in $\mathrm{LH}$, but this preovulatory surge is not sufficient to cause ovulation without the primary increase in tonic levels of LH brought about by sensory stimulation from the VNO. These conclusions support the hypothesis that pheromones, produced by the male and detected by the VNO in the female, are a factor in the synchronization of ovulation that occurs during the Whitten effect in South African indigenous does.

\section{References}

[1] M. Halpern, "The organization and function of the vomeronasal system," Annual Review of Neuroscience, vol. 10, pp. 325362, 1987.

[2] W. K. Whitten, "Modification of the oestrous cycle of the mouse by external stimuli associated with the male; changes in the oestrous cycle determined by vaginal smears," The Journal of Endocrinology, vol. 17, no. 3, pp. 307-313, 1958.

[3] M. A. Johns, H. H. Feder, B. R. Komisaruk, and A. D. Mayer, "Urine-induced reflex ovulation in anovulatory rats may be a vomeronasal effect," Nature, vol. 272, no. 5652, pp. 446-448, 1978.

[4] A. Gallego and J. F. Sanchez-Criado, "Pheromonal regulation of the estrous cycle in the female rat by the accessory olfactory system," Acta Endocrinologica Supplementum, vol. 225, p. 256, 1979.

[5] E. J. Underwood, F. L. Shier, and N. Davenport, "Studies in sheep husbandry in W.A.V. The breeding season in Merino, crossbred and British breed ewes in the agricultural districts," Journal of Agriculture, Western Australia, vol. 11, pp. 135-143, 1944.

[6] P. G. Schinkel, "The effect of the ram on the incidence and occurrence of oestrus in ewes," Australian Veterinary Journal, vol. 30, pp. 189-195, 1954.

[7] T. W. Knight, A. J. Peterson, and E. Payne, "The ovarian and hormonal response of the ewe to stimulation by the ram early in the breeding season," Theriogenology, vol. 10, no. 5, pp. 343353, 1978.

[8] D. G. Edger and D. A. Bilkey, "The influence of rams on the onset of the breeding season in ewes," Proceedings of the New Zealand Society of Animal Production, vol. 23, pp. 79-87, 1963.

[9] C. M. Oldham, G. B. Martin, and T. W. Knight, "Stimulation of seasonally anovular Merino ewes by rams. I. Time from introduction of the rams to the preovulatory LH surge and ovulation," Animal Reproduction Science, vol. 1, no. 4, pp. 283290, 1979.

[10] M. Shelton, "The influence of the presence of a male goat on the initiation of oestrus cycling and ovulation of Angora does," Journal of Animal Science, vol. 19, pp. 368-375, 1960.
[11] R. S. Ott, D. R. Nelson, and J. E. Hixon, "Effect of presence of the male on initiation of estrous cycle activity of goats," Theriogenology, vol. 13, no. 2, pp. 183-190, 1980.

[12] J. M. Chesworth and A. Tait, "A note on the effect of presence of rams upon the amount of luteinizing hormone in the blood of ewes," Animal Production, vol. 19, pp. 107-110, 1974.

[13] G. B. Martin, C. M. Oldham, and D. R. Lindsay, "Increased plasma LH levels in seasonally anovular merino ewes following the introduction of rams," Animal Reproduction Science, vol. 3, no. 2, pp. 125-132, 1980.

[14] P. Poindron, Y. Cognie, F. Gayerie, P. Orgeur, C. M. Oldham, and J. P. Ravault, "Changes in gonadotrophins and prolactin levels in isolated (seasonally or lactationally) anovular ewes associated with ovulation caused by the introduction of rams," Physiology and Behavior, vol. 25, no. 2, pp. 227-236, 1980.

[15] D. T. Baird and R. J. Scaramuzzi, "Changes in the secretion of ovarian steroids and pituitary luteinizing hormone in the peri ovulatory period in the ewe: the effect of progesterone," Journal of Endocrinology, vol. 70, no. 2, pp. 237-245, 1976.

[16] H.-D. Dellmann, "Endocrine system," in Textbook of Veterinary Histology, H.-D. Dellmann and E. M. Brown, Eds., pp. 373-399, Lea and Febiger, Philadelphia, Pa, USA, 1976.

[17] P. D. Morgan, G. W. Arnold, and D. R. Lindsay, "A note on the mating behaviour of ewes with various senses impaired," Journal of Reproduction and Fertility, vol. 30, no. 1, pp. 151152, 1972.

[18] T. W. Knight, "Ram-induced stimulation of ovarian and oestrous activity in anoestrous ewes-a review," Proceedings of the New Zealand Society of Animal Production, vol. 43, pp. 7-11, 1983.

[19] P. Chemineau, F. Levy, and J. Thimonier, "Effects of anosmia on LH secretion, ovulation and oestrous behaviour induced by males in the anovular Creole goat," Animal Reproduction Science, vol. 10, no. 2, pp. 125-132, 1986.

[20] J. Cohen-Tannoudji, A. Locatelli, and J. P. Signoret, "Nonpheromonal stimulation by the male of $\mathrm{LH}$ release in the anoestrous ewe," Physiology and Behavior, vol. 36, no. 5, pp. 921-924, 1986.

[21] G. P. Pearce and C. M. Oldham, "Importance of non-olfactory ram stimuli in mediating ram-induced ovulation in the ewe," Journal of Reproduction and Fertility, vol. 84, no. 1, pp. 333339, 1988.

[22] R. H. Watson and H. M. Radford, "The influence of rams on the onset of oestrus in Merino ewes in the spring," Australian Journal of Agricultural Research, vol. 11, pp. 65-71, 1960.

[23] T. W. Knight and P. R. Lynch, "Source of ram pheromones that stimulate ovulation in the ewe," Animal Reproduction Science, vol. 3, no. 2, pp. 133-136, 1980.

[24] T. W. Knight, H. R. Tervit, and P. R. Lynch, "Effects of boar pheromones, ram's wool and presence of bucks on ovarian activity in anovular ewes early in the breeding season," Animal Reproduction Science, vol. 6, no. 2, pp. 129-134, 1983.

[25] M. Keller, S. Pierman, Q. Douhard, M. J. Baum, and J. Bakker, "The vomeronasal organ is required for the expression of lordosis behaviour, but not sex discrimination in female mice," European Journal of Neuroscience, vol. 23, no. 2, pp. 521-530, 2006.

[26] J. B. Powers and S. S. Winans, "Vomeronasal organ: critical role in mediating sexual behavior of the male hamster," Science, vol. 187, no. 4180, pp. 961-963, 1975.

[27] S. S. Winans and J. B. Powers, "Olfactory and vomeronasal deafferentation of male hamsters: histological and behavioral analyses," Brain Research, vol. 126, no. 2, pp. 325-344, 1977. 
[28] A. Fleming, F. Vaccarino, L. Tambosso, and P. Chee, "vomeronasal and olfactory system modulation of maternal behavior in the rat," Science, vol. 203, no. 4378, pp. 372-374, 1979.

[29] J. Reynolds and E. B. Keverne, "The accessory olfactory system and its role in the pheromonally mediated suppression of oestrus in grouped mice," Journal of Reproduction and Fertility, vol. 57, no. 1, pp. 31-35, 1979.

[30] J. F. Bellringer, P. M. Hester Pratt, and E. B. Keverne, "Involvement of the vomeronasal organ and prolactin in pheromonal induction of delayed implantation in mice," Journal of Reproduction and Fertility, vol. 59, no. 1, pp. 223228, 1980.

[31] N. Kaneko, E. A. Debski, M. C. Wilson, and W. K. Whitten, "Puberty acceleration in mice. II. Evidence that the vomeronasal organ is a receptor for the primer pheromone in male mouse urine," Biology of Reproduction, vol. 22, no. 4, pp. 873-878, 1980.

[32] M. N. Lehman, S. S. Winans, and J. B. Powers, "Medial nucleus of the amygdala mediates chemosensory control of male hamster sexual behavior," Science, vol. 210, no. 4469, pp. $557-560,1980$.

[33] N. J. Bean, "Olfactory and vomeronasal mediation of ultrasonic vocalizations in male mice," Physiology and Behavior, vol. 28, no. 1, pp. 31-37, 1982.

[34] N. J. Bean, "Modulation of agonistic behavior by the dual olfactory system in male mice," Physiology and Behavior, vol. 29, no. 3, pp. 433-437, 1982.

[35] J. E. Sanchez-Criado, "Involvement of the vomeronasal system in the reproductive physiology of the rat," in Olfaction and Endocrine Regulation, E. Breipohl, Ed., pp. 209-221, IRL Press, London, UK, 1982.

[36] C. J. Wysocki, J. Nyby, G. Whitney, G. K. Beauchamp, and Y. Katz, "The vomeronasal organ: primary role in mouse chemosensory gender recognition," Physiology and Behavior, vol. 29, no. 2, pp. 315-327, 1982.

[37] C. J. Wysocki, Y. Katz, and R. Bernhard, "The male vomeronasal organ mediates female-induced testosterone surges in mice," Biology of Reproduction, vol. 28, no. 4, pp. 917 922, 1983.

[38] A. N. Clancy, A. Coquelin, F. Macrides, R. A. Gorski, and E. P. Noble, "Sexual behaviour and aggression in male mice: involvement of the vomeronasal system," Journal of Neuroscience, vol. 4, pp. 2222-2229, 1984.

[39] A. N. Clancy, F. Macrides, A. G. Singer, and W. C. Agosta, "Male hamster copulatory responses to a high molecular weight fraction of vaginal discharge: effects of vomeronasal organ removal," Physiology and Behavior, vol. 33, no. 4, pp. 653-660, 1984.

[40] A. Coquelin, A. N. Clancy, and F. Macrides, "Pheromonally induced release of luteinizing hormone in male mice: involvement of the vomeronasal system," Journal of Neuroscience, vol. 4, no. 9, pp. 2230-2236, 1984.

[41] K. Booth and L. S. Katz, "Role of the vomeronasal organ in neonatal offspring recognition in sheep," Biology of Reproduction, vol. 63, no. 3, pp. 953-958, 2000.

[42] J. Kratzing, "The structure of the vomeronasal organ in the sheep," Journal of Anatomy, vol. 108, no. 2, pp. 247-260, 1971.

[43] E. R. Liman, "Pheromone transduction in the vomeronasal organ," Current Opinion in Neurobiology, vol. 6, no. 4, pp. 487493, 1996.

[44] R. Tirindelli, C. Mucignat-Caretta, and N. J. P. Ryba, "Molecular aspects of pheromonal communication via the vomeronasal organ of mammals," Trends in Neurosciences, vol. 21, no. 11, pp. 482-486, 1998.

[45] C. Dulac and R. Axel, "A novel family of genes encoding putative pheromone receptors in mammals," Cell, vol. 83, no. 2, pp. 195-206, 1995.

[46] R. E. McCotter, "The connection of the vomeronasal nerves with the accessory olfactory bulb in the opossum and other mammals," Anatomical Record, vol. 6, pp. 299-318, 1912.

[47] P. C. Barber and P. M. Field, "Autoradiographic demonstration of afferent connections of the accessory olfactory bulb in the mouse," Brain Research, vol. 85, no. 2, pp. 201-203, 1975.

[48] G. A. Kevetter and S. S. Winans, "Connections of the corticomedial amygdala in the golden hamster. I. Efferents of the 'vomeronasal amygdala,' Journal of Comparative Neurology, vol. 197, no. 1, pp. 81-98, 1981.

[49] F. Scalia and S. S. Winans, "The differential projections of the olfactory bulb and accessory olfactory bulb in mammals," Journal of Comparative Neurology, vol. 161, no. 1, pp. 31-55, 1975.

[50] R. D. Estes, "The role of the vomeronasal organ in mammalian reproduction," Mammalia, vol. 36, pp. 315-341, 1972.

[51] C. Beltramino and S. Taleisnik, "Effect of electrochemical stimulation in the olfactory bulbs on the release of gonadotropin hormones in rats," Neuroendocrinology, vol. 28, no. 5, pp. 320-328, 1979.

[52] M. E. Velasco and S. Taleisnik, "Release of gonadotropins induced by amygdaloid stimulation in the rat," Endocrinology, vol. 84, no. 1, pp. 132-139, 1969.

[53] C. Beltramino and S. Taleisnik, "Facilitatory and inhibitory effects of electrochemical stimulation of the amygdala on the release of luteinizing hormone," Brain Research, vol. 144, no. 1, pp. 95-107, 1978.

[54] C. Beltramino and S. Taleisnik, "Dual action of electrochemical stimulation of the bed nucleus of the stria terminalis on the release of LH," Neuroendocrinology, vol. 30, no. 4, pp. 238-242, 1980.

[55] M. Schwanzel-Fukuda and D. W. Pfaff, "Origin of luteinizing hormone releasing hormone neurons," Nature, vol. 338, pp. 161-164, 1989.

[56] S. Wray, A. Nieburgs, and S. Elkabes, "Spatiotemporal cell expression of luteinizing hormone-releasing hormone in the prenatal mouse: evidence for an embryonic origin in the olfactory placode," Developmental Brain Research, vol. 46, no. 2, pp. 309-318, 1989.

[57] K. Yoshida, S. A. Tobet, J. E. Crandall, T. P. Jimenez, and G. A. Schwarting, "The migration of luteinizing hormone-releasing hormone neurons in the developing rat is associated with a transient, caudal projection of the vomeronasal nerve," Journal of Neuroscience, vol. 15, no. 12, pp. 7769-7777, 1995.

[58] K. Yoshida, U. Rutishauser, J. E. Crandall, and G. A. Schwarting, "Polysialic acid facilitates migration of luteinizing hormone-releasing hormone neurons on vomeronasal axons," Journal of Neuroscience, vol. 19, no. 2, pp. 794-801, 1999.

[59] C. Quanbeck, N. M. Sherwood, R. P. Millar, and E. Terasawa, "Two populations of luteinizing hormone-releasing hormone neurons in the forebrain of the rhesus macaque during embryonic development," Journal of Comparative Neurology, vol. 380, no. 3, pp. 293-309, 1997.

[60] G. A. Schwarting, D. Raitcheva, E. P. Bless, S. L. Ackerman, and S. Tobet, "Netrin 1-mediated chemoattraction regulates the migratory pathway of LHRH neurons," European Journal of Neuroscience, vol. 19, no. 1, pp. 11-20, 2004. 
[61] P. G. Schinkel, "The effect of the presence of the ram on the ovarian activity of the ewe," Australian Journal of Agricultural Research, vol. 5, pp. 465-469, 1954.

[62] C. M. Oldham and G. B. Martin, "Stimulation of seasonally anovular Merino ewes by rams. II. Premature regression of ram-induced corpora lutea," Animal Reproduction Science, vol. 1, no. 4, pp. 291-295, 1979.

[63] J. P. Signoret and D. R. Lindsay, "The male effect in domestic mammals: effect on LH secretion and ovulation-importance of olfactory cues," in Olfaction and Endocrine Regulation, W. Breipohl, Ed., pp. 63-72, IRL Press, London, UK, 1982.

[64] G. Rajendren, C. A. Dudley, and R. L. Moss, "Role of the vomeronasal organ in the male-induced enhancement of sexual receptivity in female rats," Neuroendocrinology, vol. 52, no. 4, pp. 368-372, 1990.

[65] H. Gelez, E. Archer, D. Chesneau, T. Magallon, and C. Fabre-Nys, "Inactivation of the olfactory amygdala prevents the endocrine response to male odour in anoestrus ewes," European Journal of Neuroscience, vol. 19, no. 6, pp. 15811590, 2004.

[66] D. R. Lindsay and J. P. Signoret, "Influence of behaviour on reproduction," in Proceedings of the International Congress on Animal Reproduction and Artificial Insemination, vol. 1, pp. 83-92, 1980.

[67] S. W. Walkden-Brown, B. J. Restall, and S. Henniawati, "The male effect in the Australian cashmere goat. 3. Enhancement with buck nutrition and use of oestrous females," Animal Reproduction Science, vol. 32, no. 1-2, pp. 69-84, 1993.

[68] A. Perkins and J. A. Fitzgerald, "The behavioral component of the ram effect: the influence of ram sexual behavior on the induction of estrus in anovulatory ewes," Journal of Animal Science, vol. 72, no. 1, pp. 51-55, 1994.

[69] J. A. Flores, F. G. Véliz, J. A. Pérez-Villanueva et al., "Male reproductive condition is the limiting factor of efficiency in the male effect during seasonal anestrus in female goats," Biology of Reproduction, vol. 62, no. 5, pp. 1409-1414, 2000.

[70] D. C. Skinner, S. D. Cilliers, and J. D. Skinner, "Effect of ram introduction on the oestrous cycle of springbok ewes (Antidorcas marsupialis)," Reproduction, vol. 124, no. 4, pp. 509-513, 2002.

[71] M. Shelton, "Goats: influence of various exteroceptive factors in initiation of oestrus and ovulation," International Goat and Sheep Research, vol. 1, pp. 156-162, 1980. 

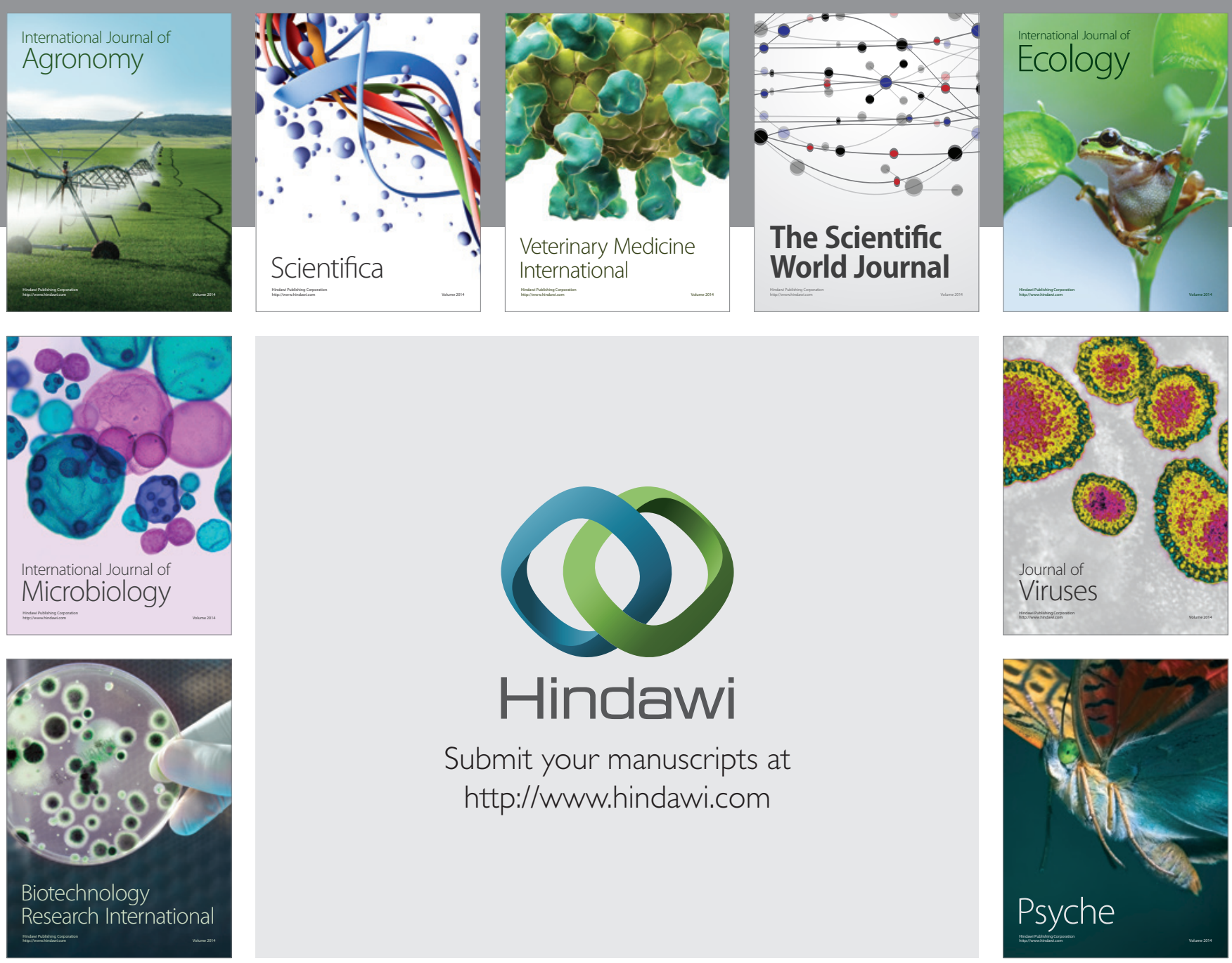

Submit your manuscripts at

http://www.hindawi.com
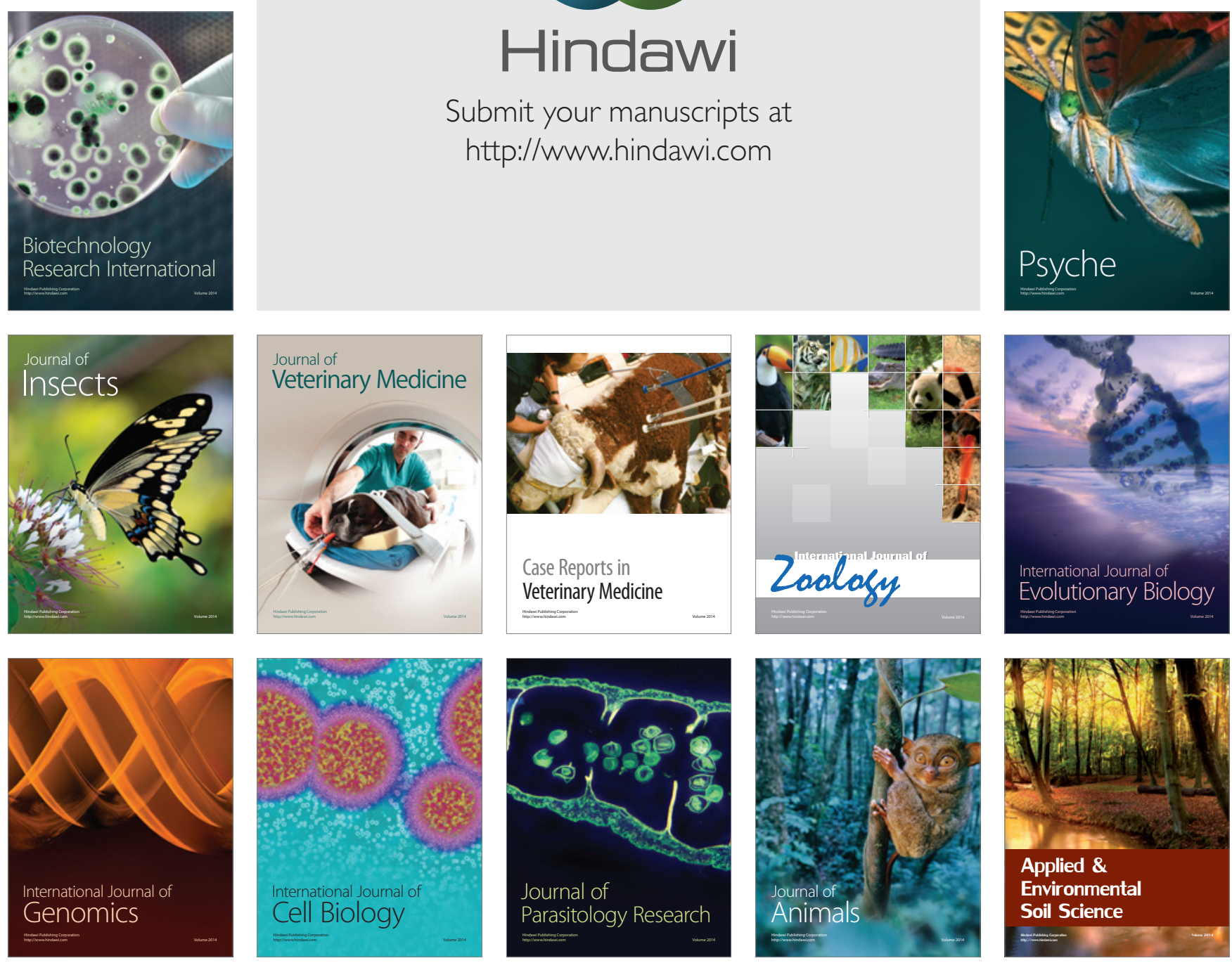